\title{
Gambaran malaria pada anak di RSU GMIM Bethesda Tomohon periode 2011-2015
}

\author{
${ }^{1}$ Boy A. I. Paendong \\ ${ }^{2}$ Suryadi N. N. Tatura \\ ${ }^{2}$ Hesti Lestari
}

\author{
${ }^{1}$ Kandidat Skripsi Fakultas Kedokteran Universitas Sam Ratulangi Manado \\ ${ }^{2}$ Bagian Ilmu Kesehatan Anak Fakultas Kedokteran Universitas Sam Ratulangi Manado \\ Email: andre_zukit@yahoo.co.id
}

\begin{abstract}
Malaria is an endemic disease that is often found in the world, particularly in tropic areas. Four types of plasmodiums that often infect human are falciparum, vivax, malariae, and ovale. The symptoms of malaria that usually occur are fever, chills, and sweats. This study was aimed to obtain the profile of malaria in children at GMIM Bethesda Hospital Tomohon. This was a descriptive retrospective study with a cross sectional design. The results showed that of 105 children who suffered from malaria, only 92 children fulfilled the inclusion criteria. Malaria was found in the years 2011-2015. The highest percentages were age 5-9 years $(31.5 \%)$, males $(66 \%)$, plasmodium falciparum $(63 \%)$, and fever as the clinical manifestation (100\%). The manifestation of malaria such as fever, chill, and ssweating perspiring was found in $13.1 \%$ of cases and complication of severe anemia in $1,1 \%$ of cases. Most cases were treated with DHP and primaquin. Conclusion: In this study, malaria was still an endemic disease in GMIM Bethesda Hospital Tomohon, most among males aged 5-9 years. Plasmodium falciparum was the most common type and fever was the clinical manifestation mostly complained.
\end{abstract}

Keywords: malaria, plasmodium, children

\begin{abstract}
Abstrak: Malaria adalah penyakit endemis yang sering dijumpai di seluruh dunia, terutama di daerah tropis. Empat plasmodium yang biasa menginfeksi manusia yaitu falciparum, vivax, malariae, dan ovale. Gejala umum pada malaria ialah demam, menggigil, dan berkeringat. Menurut data WHO, di dunia kasus penyakit malaria pada tahun 2015 berjumlah 214 juta kasus. Di Sulawesi Utara pada tahun 2014 jumlah kasus malaria menyentuh angka 2.244 jiwa. Penelitian ini bertujuan untuk mengetahui gambaran malaria pada anak di RSU GMIM Bethesda Tomohon. Jenis penelitian ialah deskriptif retrospektif dengan desain potong lintang. Hasil penelitian menunjukkan bahwa dari 105 anak yang menderita malaria didapatkan 92 anak sebagai subjek penelitian yang memenuhi kriteria inklusi. Malaria terdapat sepanjang tahun dari 2011-2015. Mayoritas anak dengan malaria ialah usia 5-9 tahun (31,5\%), jenis kelamin laki-laki (66\%), jenis plasmodium falciparum (63\%), dan gejala klinis demam (100\%). Gejala malaria demam, menggigil, berkeringat ditemukan sebanyak $13,1 \%$ dan komplikasi anemia berat $1,1 \%$. Terapi yang banyak digunakan ialah DHP dan primakuin. Simpulan: Pada studi ini malaria masih merupakan penyakit endemik di RSU GMIM Behesda Tomohon, sering terjadi pada anak laki-laki, usia 5-9 tahun, dengan mayoritas plasmodium falciparum dan gejala klinis demam.
\end{abstract}

Kata kunci: malaria, plasmodium, anak

Malaria merupakan penyakit endemis yang sering di jumpai di seluruh dunia, terutama di daerah tropis. Kelompok yang berisiko terkena malaria ialah anak-anak dan wanita 
hamil; keadaan ini sangat memengaruhi angka kematian. Faktor yang memengaruhi perkembangan penyakit malaria ialah antara lain lingkungan, sosial, ekonomi, dan perilaku. ${ }^{1,2}$

Menurut data WHO, diperkirakan di dunia jumlah insiden penyakit malaria pada tahun 2015 berjumlah 214 juta kasus dengan angka kematian 438.000 orang. Dari jumlah tersebut kebanyakan yang meninggal akibat malaria ialah anak-anak di bawah 5 tahun. Sebagian besar kasus malaria terjadi di Afrika $80 \%$ sedangkan di Asia tenggara $10 \%$ dan bagian mediteranian 2\%. Di Asia Tenggara negara yang termasuk wilayah endemis malaria ialah Bangladesh, Bhutan, India, Indonesia, Maldives, Myanmar, Nepal, Srilanka, dan Thailand. $^{3}$

Insiden malaria pada penduduk Indonesia tahun 2013 ialah 1,9\% menurun dibandingkan tahun 2007 2,9\%. Prevalensi malaria tahun 2013 ialah 6,0\%. Lima provinsi dengan insiden dan prevalensi tertinggi ialah Papua $(9,8 \%$ dan $28,6 \%)$, Nusa Tenggara Timur (6,8\% dan $23,3 \%)$, Papua Barat (6,7\% dan 19,4\%), Sulawesi Tengah (5,1\% dan 12,5\%), dan Maluku $(3,8 \%$ dan $10,7 \%) .{ }^{4}$ Secara nasional angka kesakitan malaria selama tahun 2005-2014 cenderung menurun yaitu 4,1 per 1.000 penduduk berisiko pada tahun 2005, menjadi 0,99 per 1.000 penduduk berisiko pada tahun $2014 .^{5}$

Di Sulawesi Utara malaria termasuk sepuluh penyakit terbanyak meskipun sejak lima tahun terakhir, angka kesakitan malaria menunjukan penurunan. ${ }^{6}$ Pada tahun 2013 jumlah penderita malaria menyentuh angka 2.602 jiwa dan pada tahun 2014 menyentuh angka 2.244 jiwa, dimana terjadi penurunan angka terjadinya penyakit malaria di Sulawesi utara. ${ }^{7}$

Malaria disebabkan oleh protozoa dari genus plasmodium. Pada manusia ditemukan 4 spesies plasmodium terdiri dari: plasmodium falciparum yang menyebabkan malaria tropika, plasmodium vivax yang menyebabkan malaria tertiana, plasmodium malariae yang menyebabkan malaria kuartana, dan plasmodium ovale yang menyebabkan malaria ovale. ${ }^{8}$

Gejala klinis pada penderita malaria dikenal trias malaria yaitu demam, mengigil, dan berkeringat. Juga terdapat penderita malaria yang masuk rumah sakit dengan gejala lain tetapi kemudian didiagnosis malaria. ${ }^{8}$

Penelitian ini bertujuan untuk mengetahui gambaran penyakit malaria pada anak di RSU GMIM Bethesda Tomohon.

\section{METODE PENELITIAN}

Jenis penelitian ini ialah deskriptif retrospektif dengan desain potong lintang. Penelitian dilakukan di Bagian Ilmu Kesehatan Anak RSU GMIM Bethesda Tomohon. Sampel penelitian ialah anak dengan diagnosis malaria yang dirawat di Bagian Ilmu Kesehatan Anak RSU GMIM Bethesda Tomohon pada periode 20112015. Data diolah dengan menggunakan Microsoft Excel 2010.

\section{HASIL PENELITIAN}

Berdasarkan data rekam medik RSU GMIM BETHESDA tahun 2011 hingga 2015 didapatkan 105 anak yang dirawat dengan diagnosis malaria. Sebanyak 13 anak dieksklusi karena data rekam medik yang tidak lengkap sehingga didapatkan sebanyak 92 anak yang sesuai dengan kriteria inklusi.

Dari hasil distribusi frekuensi kasus malaria pada anak berdasarkan tahun didapatkan pada tahun 2011 berjumlah 23 anak dengan malaria dari 1.238 kasus pada anak (1,8\%); tahun 2012 berjumlah 21 anak dari 796 kasus pada anak $(2,6 \%)$; tahun 2013 berjumlah 20 anak dari 882 kasus pada anak (2,3\%); tahun 2014 berjumlah 9 anak dari 735 kasus pada anak (1,2\%); dan tahun 2015 berjumlah 19 anak dari 966 kasus pada anak (1,9\%). Total dari 2011-2015 terdapat 92 kasus malaria pada anak dari 4.617 kasus pada anak $(9,8 \%)$ (Gambar 1).

Usia dikelompokan menjadi 0-4 tahun sebanyak 17 anak (18,5\%), 5-9 tahun sebanyak 29 anak (31,5\%), 10-14 tahun sebanyak 26 anak (28,3\%), 15-18 tahun 
sebanyak 20 anak (21,7\%), sehingga di dapatkan usia 5-9 tahun yang paling banyak menderita malaria (Tabel 1)

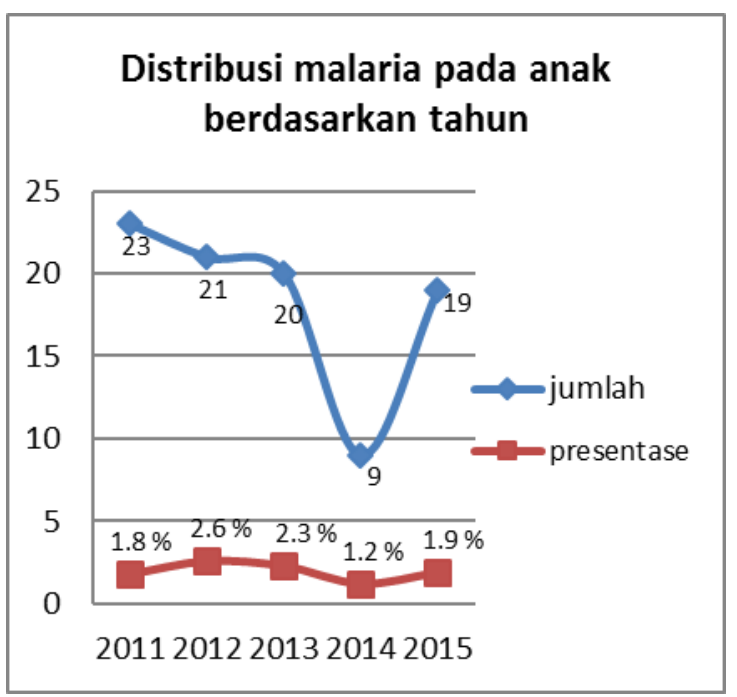

Gambar 1. Distribusi malaria pada anak berdasarkan tahun

Tabel 1. Distribusi usia

\begin{tabular}{ccc}
\hline Usia (tahun) & Jumlah anak & $\boldsymbol{\%}$ \\
\hline $0-4$ & 17 & 18,5 \\
$5-9$ & 29 & 31,5 \\
$10-14$ & 26 & 28,3 \\
$15-18$ & 20 & 21,7 \\
Total & 92 & 100 \\
\hline
\end{tabular}

Distribusi sampel menurut jenis kelamin didapatkan 61 anak dengan jenis kelamin laki-laki (66\%) dan 31 anak dengan jenis kelamin perempuan (34\%), dari 92 kasus malaria pada anak (Tabel 2).

Tabel 2. Distribusi jenis kelamin

\begin{tabular}{ccc}
\hline $\begin{array}{c}\text { Jenis } \\
\text { kelamin }\end{array}$ & $\begin{array}{c}\text { Jumlah } \\
\text { anak }\end{array}$ & \% \\
\hline Laki - Laki & 61 & 66 \\
Perempuan & 31 & 34 \\
Total & 92 & 100 \\
\hline
\end{tabular}

Berdasarkan distribusi sampel menurut jenis parasit plasmodium didapatkan dua jenis plasmodium dari empat plasmodium yang dapat menyerang manusia. Distribusi paling banyak ialah plasmodium falciparum dibandingkan plasmodium vivax (Tabel 3).
Tabel 3. Jenis plasmodium

\begin{tabular}{ccc}
\hline Plasmodium & Frekuensi & \% \\
\hline Falciparum & 58 & 63 \\
Vivax & 18 & 37 \\
Total & 92 & 100 \\
\hline
\end{tabular}

Distribusi sampel menurut gejala klinis menunjukkan bahwa dari 92 kasus malaria, gejala yang paling banyak ditemukan ialah demam (100\%), dan yang paling sedikit gejala ditemukan ialah sakit menelan $(2,2 \%)$. Gejala lain juga yang dijumpai ialah muntah $(55,4 \%)$, menggigil $(46,7 \%)$, mual (39,6\%), sakit kepala (35,9\%), berkeringat $(36,1 \%)$, sakit perut $(25,1 \%)$, batuk $(14,1 \%)$, nyeri badan $(4,3 \%)$, dan beringus $(4,3 \%)$ (Tabel 4). Gejala klinis malaria klasik yang ditemukan demam, menggigil, dan berkeringat pada 12 kasus $(13,1 \%)$ dari 92 kasus. Gejala tidak klasik demam ditemukan pada 80 kasus $(86,9 \%)$ dari 92 kasus; gejala asimtomatik atau tidak ada gejala demam tidak ditemukan (Tabel $5)$.

Tabel 4. Distribusi gejala klinis

\begin{tabular}{ccc}
\hline Gejala klinis & Jumlah & \% \\
\hline Demam & 92 & 100 \\
Muntah & 51 & 55,4 \\
Menggigil & 43 & 46,7 \\
Mual & 36 & 39,6 \\
Sakit kepala & 33 & 35,9 \\
Berkeringat & 24 & 26,1 \\
Sakit perut & 23 & 25,1 \\
Batuk & 13 & 14,1 \\
Nyeri badan & 4 & 4,3 \\
Beringus & 4 & 4,3 \\
Sakit menelan & 2 & 2,2 \\
\hline
\end{tabular}

Tabel 5. Distribusi gejala klinis malaria

\begin{tabular}{ccc}
\hline Gejala klinis & Jumlah & $\mathbf{\%}$ \\
\hline $\begin{array}{c}\text { Gejala klasik } \\
\text { (Demam+menggigil } \\
\text { + berkeringat) }\end{array}$ & 12 & 13,1 \\
$\begin{array}{c}\text { Tidak klasik } \\
\text { (Demam) }\end{array}$ & 80 & 86,9 \\
$\begin{array}{c}\text { Asimtomatik } \\
\text { (Tidak ada demam) }\end{array}$ & 0 & 0 \\
\hline
\end{tabular}

Distribusi pasien berdasarkan komplikasi mendapatkan dari 92 kasus 
hanya 1 kasus dengan komplikasi anemia berat; tidak ditemukan komplikasi lain seperti malaria serebral, gagal ginjal, edema paru, hipoglikemi, syok, perdarahan abnormal, black water fever, demam tinggi, dan hiperparasitemia (Tabel 6).

Tabel 6. Distribusi komplikasi

\begin{tabular}{ccc}
\hline Komplikasi & $\begin{array}{c}\text { Jumlah } \\
\mathbf{n = 9 2}\end{array}$ & $\mathbf{\%}$ \\
\hline Anemia & 1 & 1,1 \\
Malaria serebral & 0 & 0 \\
Gagal ginjal & 0 & 0 \\
Edema paru & 0 & 0 \\
Hipoglikemi & 0 & 0 \\
Syok & 0 & 0 \\
Perdarahan & 0 & 0 \\
abnormal & & \\
Black water fever & 0 & 0 \\
Demam Tinggi & 0 & 0 \\
Hiperparasitemia & 0 & 0 \\
\hline
\end{tabular}

Berdasarkan distribusi frekuensi terapi, didapatkan terapi malaria pada anak yang digunakan tahun 2011 yaitu DHP (Dihidroartemisinin + piperakuin $)+$ primakuin (86,9\%), Arsuamoon (Artesunate + Amodiaquine $)+$ primakuin $(13,1 \%)$; tidak ditemukan terapi kina + primakuin dan obat OAM lainya. Pada tahun 2012 terapi malaria yang digunakan ialah DHP + primakuin $(95,2 \%)$, Arsuamoon + primakuin $(4,8 \%)$; tidak ditemukan terapi kina + primakuin dan obat OAM lainya. Pada tahun 2013 terapi malaria yang digunakan ialah DHP + primakuin $(100 \%)$; tidak ditemukan terapi Arsuamoon + primakuin, kina + primakuin dan obat OAM lainya. Pada tahun 2014 terapi malaria yang diberikan ialah DHP + primakuin (100\%); tidak ditemukan terapi Arsuamoon) + primakuin, kina + primakuin dan obat OAM lainya. Pada tahun 2015 terapi malaria yang digunakan ialah DHP + primakuin $(100 \%)$; tidak ditemukan terapi Arsuamoon + primakuin, kina + primakuin dan obat OAM lainya (Gambar 2).

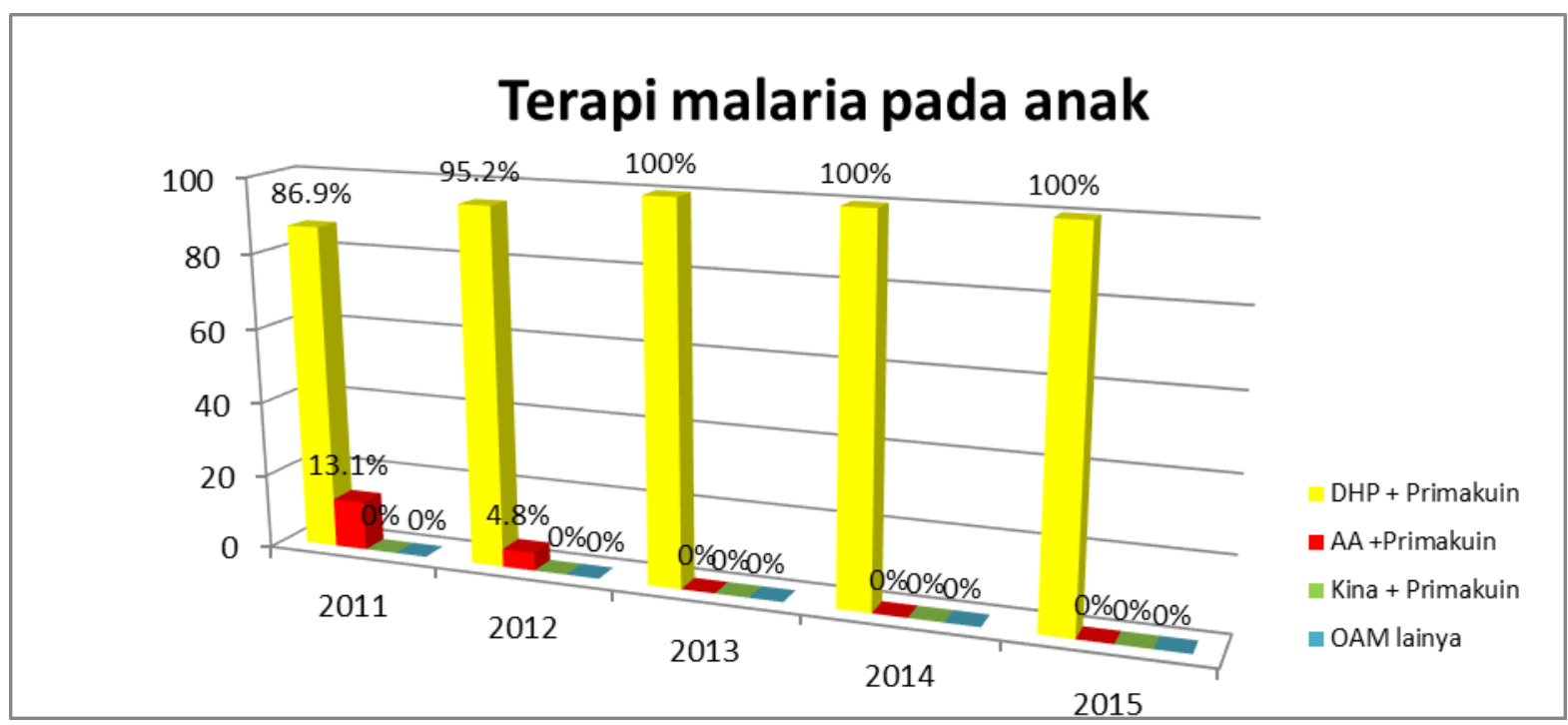

Gambar 2. Distribusi terapi

\section{BAHASAN}

Berdasarkan hasil penelitian yang dilakukan di RSU GMIM Bethesda Tomohon melalui pengambilan data rekam medik didapatkan pasien malaria pada anak yang berusia 0-18 tahun pada periode 2011-2015 yang memenuhi kriteria inklusi sebanyak 92 pasien.

Berdasarkan usia, angka kejadian tertinggi terjadi pada pasien malaria anak $n$ kelompok usia 5-9 tahun. Hal ini selaras dengan data dari Depkes ${ }^{4}$ yang menunjukkan angka kejadian malaria terbanyak pada kelompok usia 5-9 tahun. 
Berdasarkan jenis kelamin pasien lakilaki 61 kasus lebih banyak dari pada pasien perempuan 31 kasus dari total 92 kasus. Hasil penelitian ini selaras dengan penelitian Abdussalam et al. ${ }^{9}$ yang mendapatkankan laki-laki 25 kasus lebih banyak dibandingkan perempuan 20 kasus dari 45 kasus malaria pada anak di Papua barat. ${ }^{9}$ Hal ini mengasumsikan bahwa perempuan mempunyai respon imun yang lebih kuat dibandingkan laki-laki.

Berdasarkan jenis parasit plasmodium didapatkan terbanyak di antara penderita malaria pada anak ialah plasmodium falciparum (66\%). Hal ini selaras dengan hasil penelitian Nmadu et al. ${ }^{10}$ yang mendapatkan plasmodium falsiparum paling banyak di antara kasus malaria pada anak $(63 \%)$.

Berdasarkan gejala klinis didapatkan gejala yang paling banyak dijumpai ialah demam $(100 \%)$ dan yang paling sedikit gejala yang dijumpai sakit menelan $(2,2 \%)$. Gejala klinis malaria klasik yang ditemukan yaitu trias demam, menggigil, dan berkeringat sebanyak $13,1 \%$ sedangkan gejala tidak klasik demam $86,9 \%$. Kasus dengan gejala asimtomatik atau tidak ada gejala demam tidak ditemukan. Selaras dengan hasil penelitian Siahaan ${ }^{11}$ yang menyatakan bahwa demam paling banyak dijumpai pada pasien malaria sebesar $64,7 \%$ dan gejala klasik malaria sebesar $13,7 \%$ tidak selalu ditemukan.

Berdasarkan komplikasi didapatkan dari 92 kasus malaria pada anak hanya 1 kasus yang terkena komplikasi anemia berat. Hasil penelitian ini berbeda dengan hasil penelitian Satari ${ }^{12}$ yang menemukan 68 kasus malaria pada anak dan yang terkena komplikasi hepatomegali 23 kasus, anemia berat 18 kasus, splenomegali 6 kasus, ikterus 2 kasus, syok 2 kasus, dan perdarahan 1 kasus. $^{12}$

Berdasarkan terapi malaria pada anak DHP + primakuin yang paling banyak digunakan yaitu: tahun 2011, 86,9\% dari 23 kasus; tahun 2012, 95,2\% dari 21 kasus; tahun 2013, 100\% dari 20 kasus; tahun 2014, 100\% dari 9 kasus; dan tahun 2015, $100 \%$ dari 19 kasus. Hasil ini sejalan dengan hasil penelitian Wadana et al. ${ }^{13}$ yang melaporkan bahwa DHP + primakuin paling sering digunakan untuk kasus malaria pada anak yaitu 20 dari 41 kasus $(48,7 \%)$.

\section{SIMPULAN}

Malaria masih merupakan penyakit endemis di RSU GMIM Bethesda Tomohon, paling sering terjadi pada anak laki-laki, usia 5-9 tahun dengan penyebab Plasmodium falciparum dan keluhan utama demam. Pada sebagian kasus ditemukan gejala klasik malaria sedangkan komplikasi berupa anemia berat hanya pada 1 kasus. Terapi yang paling banyak digunakan ialah DHP dan primakuin.

\section{SARAN}

1. Penelitian selanjutnya dapat dilakukan dengan metode analitik terhadap gejala klasik pada malaria dan yang asimtomatik secara lebih rinci termasuk tes serologik dan daerah asal pasien.

2. Diharapkan bagi tenaga kesehatan untuk meningkatkan pengetahuan, ketrampilan, dan kecakapan dalam melakukan anamnesis yang lengkap dan tepat.

3. Perlu adanya kesadaran masyarakat akan pentingnya kebersihan lingkungan serta tindakan nyata untuk mencegah terjadinya penyakit malaria dan pergiat lagi program pemerintah tentang penyuluhan malaria dengan memakai kelambu tidur, obat anti nyamuk dan memakai pakaian berlengan panjang dan celana panjang jika harus keluar pada malam hari.

\section{DAFTAR PUSTAKA}

1. Lee JE, Tatura S, Lestari H. Hubungan status gizi dengan tingkat kepadatan parasit malaria pada anak. $\mathrm{eCl}$. 2016;4(1).

2. Hall BF, Fauci AS. Malaria control, elimination, and eradication: The role of the evolving biomedical research agenda. Perspective. 2009;200:163943. 
3. WHO Global Malaria Programme. World malaria report, 2015.

4. Balitbang Kesehatan Kemenkes R.I Riset Kesehatan Dasar. Jakarta: Balitbang Kesehatan Kemenkes RI, 2013.

5. Kementrian Kesehatan RI. Sekertariat Jendral Profil Kesehatan Indonesia Tahun 2014. Jakarta: Kementrian Kesehatan RI, 2015.

6. Tatura SN. Efikasi obat kloroquine, kina, artesunate-SP, artesunate-amodiaquine, artesunat-lumafentrin pada anak malaria falciparum di BLU RSUP Prof. Dr. R. D. Kandou Manado. Sari Pediatri. 2009;10;417-23.

7. Database kesehatan per provinsi. Kementrian Kesehatan RI [cited 2016 Agustus 29]. Available from: http://www.bankdata.depkes.go.id/nasi onal/public/report/createtablepit

8. Soedarmo SS, Garna H, Hadinegoro SR, Satari HI. Buku Ajar Infeksi \& Pediatri Tropis (2nd ed). Jakarta: Bagian Ilmu Kesehatan Anak FKUI, 2002; p. 408-36.
9. Abdussalam R, Krimadi RN, Siregar R, Lestari ED, Salimo H. Profil infeksi plasmodium, anemia dan status nutrisi pada malaria anak di RSUD Scholoo Keyen, Kabupaten Sorong Selatan. Sari Pediatri. 2016;17:446-9.

10. Namdu PM, Peter E, Alexander P, Koggie AZ, Maikenti JI. The prevalence of malaria in children between the ages 215 vVsiting Gwarinpa General Hospital Life-Camp, Abuja, Nigeria. J Health Sci. 2015;5:47-51.

11. Siahaan L. Gejala dan tanda klinis malaria di daerah endemis. Maj Kedok Indo. 2008;58:211-5.

12. Satari HI. Pola penyakit malaria pada anak di RSU Manna Bengkulu Selatan. Sari Pediatri. 2002;3:141-6.

13. Wadana CP, Krimadi RN, Siregar R, Lestri ED, Salimo H. Profil terapi artemisinin combination therapy (ACT) pada malaria anak di RSUD. Scholoo Keyen, Kabupaten Sorong Selatan, Papua Barat. Sari Pediatri. 2016;17:323-26. 